\title{
Using a new socioepidemiological questionnaire to analyse associations between intergenerational upward social mobility and body fat distribution: A pilot study with the Oxford BioBank cohort
}

\author{
Eli, K.1, 2, Karpe, F.3, 4, and Ulijaszek, S.1
}

1 Unit for Biocultural Variation and Obesity, School of Anthropology and Museum Ethnography, University of Oxford, Oxford, UK

2 Division of Health Sciences, Warwick Medical School, University of Warwick, Coventry, UK

3 Oxford Centre for Diabetes, Endocrinology and Metabolism (OCDEM), University of Oxford, Oxford, UK

4 NIHR Oxford Biomedical Research Centre (BRC), OUHFT, Oxford, UK

\begin{abstract}
Background: As measured through body mass index (BMI), obesity is more prevalent among upwardly mobile adults than among adults who were born into middle-class families. Although BMI reflects general adiposity, the health risks of being overweight are more strongly associated with abdominal adiposity. Because chronic disease is associated with socioeconomic status, it is important to investigate associations between social mobility and fat distribution.

Methods: A new socioepidemiological questionnaire was developed, qualitatively validated and administered to Oxford BioBank participants in a pilot study. Sex-specific ANOVA analyses were conducted to investigate associations between participant occupational class and adiposity, paternal occupational class and adiposity, and upward occupational mobility relative to father and adiposity. A main aim of these analyses was to determine whether using the questionnaire would lead to the expected directional effect of fat distribution in relation to paternal social class, and thereby support the questionnaire's future use.
\end{abstract}

Results: 280 participants (166 women, 114 men; age 32-67 years; mean age 47.7 years, median age 49 years) completed the questionnaire. Men whose father was of occupational class 2 or 3 (intermediate or routine/manual occupations) had higher mean BMI, total body fat percentage, android fat mass, and android-to-gynoid fat mass ratio than men whose father was of occupational class 1. Women whose father was of occupational class 2 or 3 had higher mean BMI, total body fat percentage, android fat mass, and gynoid fat mass than women whose father was of occupational class 1 . Among men, upward occupational mobility was not associated with fatness measures. Among women, upward occupational mobility was associated with higher total body fat percentage, android fat mass, and gynoid fat mass.

Conclusion: The expected directional effect was found, thereby supporting the reliability of socioepidemiological questionnaire. Upward mobility did not appear to change the effects of childhood social class on adiposity and body fat distribution, and might have increased 
adverse health effects among women. Future research using the socioepidemiological questionnaire should investigate complex associations between gender, occupational and educational mobility, adiposity, and health outcomes. 
What is already known on this subject:

Adults who experience upward social mobility have higher disease burdens than people who were born into middle class families. A notable example is obesity (as measured through body mass index), which is nearly as prevalent among upwardly mobile adults as it is in their social class of origin. The limited effects of upward social mobility on body weight seem to indicate that risk exposures during childhood, which are usually related to socioeconomic disadvantage, are more influential than adult socioeconomic status in determining health throughout the lifecourse.

What this study adds:

This study is among the first to analyze how adiposity and body fat distribution might be associated with social class and social mobility in men and women. The analysis shows that, for both men and women, father's occupational class is significantly and inversely associated with adiposity, whereas associations between participant's occupational class and adiposity appear to be weaker. Importantly, among women, upward mobility is associated with higher total body fat percentage, android fat mass, and gynoid fat mass. The results suggest that upward mobility might not change the effects of childhood social class on adiposity and body fat distribution, and might even increase adverse health effects among women. 


\section{Introduction}

Although upwardly mobile adults are more likely to be healthier than their class of origin peers, they are still more likely to have higher disease burdens than their class of destination peers (Blane et al., 2002). Cohort and retrospective studies have consistently found complex associations between social mobility and health status. While social class has inverse relationships with markers of health status (Marmot et al., 1997; Rahkonen et al., 1997; Thayer and Kuzawa, 2011), upward social mobility has limited effects on health status (Poulton et al., 2002). Where body mass index (BMI) is concerned, the prevalence of obesity among upwardly mobile adults is either similar to that in their class of origin (Heraclides \& Brunner, 2010), or situated about midway between prevalence rates in their class of origin and their class of destination (Langenberg et al., 2003). Notably, downward social mobility has pronounced adverse effects on body weight and health (Heraclides \& Brunner, 2010), although the downwardly mobile may have a lower disease burden compared to their class of destination peers (Blane et al., 2002).

The limited effects of upward social mobility on body weight and health seem to indicate that risk exposures during childhood - exposures usually related to socioeconomic disadvantage are more influential than adult socioeconomic status in determining health throughout the lifecourse (Ball and Mishra, 2005; Giskes et al., 2008; Kestila et al., 2009; Langenberg et al., 2003; Langenberg et al., 2006; Van De Mheen et al., 1997)Recent evidence has shown that high BMI tracks into adulthood among those most socioeconomically disadvantaged in childhood (Norris et al., 2019). Thus, within a person's lifetime, upward social mobility may not undo the adverse health effects of disadvantage accumulated during childhood and adolescence (Kestila et al., 2009; Poulton et al., 2002; Power and Matthews, 1997). The apparently critical influence of socioeconomically-mediated childhood risk exposures points to possible links between social class, social mobility, and epigenetics (Thayer and Kuzawa, 2011). From a trans-generational perspective, this suggests that a parent's upward social mobility might have positive influence on the health status of offspring born subsequently.

While the extant literature on associations between social mobility and obesity has focused on body mass index (BMI)-measured obesity, BMI is an indirect and imperfect measure of bodily fatness (Ulijaszek 2017). Furthermore, adipose tissue is not homogeneous, with notable differences between abdominal and gluteofemoral (hip, thigh and leg) adiposity. Compared to BMI-measured obesity, abdominal obesity is a stronger indicator of health risk, and is closely related to the development of cardiovascular disease and type two diabetes mellitus; in contrast, gluteofemoral fatness is associated with healthier cardiovascular and metabolic profiles (Snijder et al 2004; Yusuf et al 2005; Vasan et al 2018). These opposing relationships may reflect intrinsic characteristics of individual fat depots (Karpe and Pinnick 2015), the regional distribution of fat being important in both metabolism and hormonal responsiveness. Sex-based differences in body fat distribution are also important: women have greater overall bodily fatness than men, with greater fatness in the gluteofemoral region, while men have greater abdominal fatness (Bredella 2017). Notably, raised serum triglycerides, low high density lipoprotein (HDL) cholesterol and high insulin levels are positively associated with fat around the trunk and waist (Yim et al 2008). Differences in body fat distribution and regional adipose tissue cellularity appear to be key to sex-based differences in metabolic health and chronic disease risk, although reasons for these differences, at least according to the development of different adipose tissue depots, remain 
unclear (Karastergiou and Fried 2017). Given the importance of fat distribution in health risk, relying on BMI measures alone is insufficient when attempting to understand associations between social class, social mobility, obesity, and health risk.

This manuscript reports on an analysis of associations between intergenerational social mobility and detailed measurements of body fat distribution among UK-based women and men. The analysis draws on a dataset developed through two studies in which a new socioepidemiological questionnaire was administered to Oxford BioBank participants. These datasets brought together participants' clinically-measured weight, height, and fat distribution data derived from whole body dual X-ray absorptiometry (DEXA) scan with their questionnaire responses, which focused on ascertaining various measures of socioeconomic status, social mobility, and wellbeing. The present study was designed as a pilot to investigate the performance of the questionnaire. This pilot study's aim is therefore twofold: (1) to determine whether using the questionnaire would lead to the expected directional effect of fat distribution in relation to paternal social class, and thereby support the questionnaire's future use, and (2) to investigate how body fat distribution might be associated with social class and social mobility in both men and women.

\section{Methods}

Questionnaire design and development

The Socioepidemiological Questionnaire, developed by the study team, has three subscales: socioeconomic status, social mobility, and well-being. The socioeconomic status subscale aims to measure current social class status, as expressed through economic capital and social capital; this subscale should capture the extent of current social connections, economic security, and potential for empowered participation in society. The social mobility subscale aims to measure movement from past to current socioeconomic status, across generations and within the participant's own generation; this subscale should capture changes in both economic capital and social capital. The wellbeing subscale aims to measure current health as defined by the World Health Organization (1948); this subscale should capture health across physical, social and emotional dimensions.

Each of the three subscales includes several domains. The socioeconomic status subscale includes the domains of education, income, housing, material assets, current occupation, (in)security, and social capital. The social mobility subscale includes the domains of intergenerational education, childhood household, and occupational history. The wellbeing subscale includes the domains of risk behaviours, life-course stressors, relationships, and emotional, social and physical wellness.

Each domain includes several proxy variables; some of these are similar to variables used in earlier studies, to ensure comparability, while others are novel, reflecting innovations in the literatures on health inequalities and social mobility (Law, Savage, and Ruppert 2011). Our proxy variable selection process sought to increase the diversity of life experiences captured in a questionnaire format. To select proxy variables and formulate questions that capture these variables, we first consulted established social class and social mobility surveys through UK Data Archive, including: The BBC Great British Class Survey (Savage et al., 2011-2013); Occupational and Social Mobility (Goldthorpe, 1974); General Household Survey (National Statistics, 2005); and the Social Capital Harmonised Question Set (Green and Fletcher, 2003). 
We then supplemented with variables gleaned from other sources, such as the CDC Healthy Days Measure (CDC HRQOL-14) (Centers for Disease Control and Prevention, 2000).

\section{Cognitive and face validation procedures}

After the candidate variables were identified and the first version of the questionnaire constructed, we conducted two rounds of validation. Validation procedures were reviewed and approved by the University of Oxford's School of Anthropology and Museum Ethnography Research Ethics Committee (SAME REC), as part of the larger study (see under "participant recruitment and data collection"), and all participants in both rounds of validation received detailed information sheets about the study and provided informed consent.

To establish the content validity of the questionnaire, a cross-disciplinary expert group of research students, faculty and research staff $(n=8)$ reviewed the full (66 item) questionnaire, as well as 10 additional candidate questions. The participants rated each question for relevance on a 1-4 Likert scale and provided verbal feedback. An example of the validation questionnaire administered to experts is given in the appendix.

The main concerns identified by the expert group were the absence of questions about grandmothers' and siblings' socioeconomic status, and the presence of several questions that required information which participants would be unlikely to remember (e.g., questions on grandparents' educational attainment). Based on the expert group's relevance scale scores, questions that scored highly on the relevance scale were retained in the second version of the questionnaire. Based on the expert group's verbal feedback, other variables (and subsequently, corresponding questions) were added. The new variables added were: grandparents' ages at school leaving; grandmothers' education; grandmothers' occupation; siblings' occupations; parents' health at 45 years, comparison of current and childhood neighbourhoods; sleep quality. In total, the revised questionnaire included 68 items.

To establish the face validity of the revised, 68-item questionnaire, eight Oxford BioBank participants (four women and four men) filled out the 68-item questionnaire in one-on-one cognitive interview sessions with an experienced anthropologist (first author). The participants talked through the questionnaire-taking process, sharing their reflections on the questions and answer options. After they completed their questionnaires, the first author asked the participants about the issues they flagged. The discussion aimed at generating suggestions for revision, so the questionnaire would better reflect the participants' experience. The main concerns identified through the face validity phase focused on the need to include working class education experiences, such as job-related skills and training certifications, the complexity of having multiple occupations and fluctuating incomes, and the importance of considering the historical context of parental and grandparental educational attainment. Participants also emphasized the need to account for their partners' incomes, occupations and debts in establishing economic (in)security, as well as the need to account for hardships associated with caring for an ailing relative, and the importance of asking about the respondents' adult children's occupations to establish a fuller understanding of familial aspirational trajectories. 
Based on the cognitive interviews, additional questions were introduced and others refined. The following key variables were introduced: business ownership; partner's financial security; household income; parents' and grandparents' ages at school leaving (contextualized by birth years); adult children's occupations; caring for a relative with a serious illness; experiences of discrimination or violence before and after age 16. In total, the revised - and current - version of the questionnaire includes 90 items.

\section{Participant recruitment and data collection}

Participants were recruited through the Oxford BioBank, a collection of bio-data from approximately 8,000 healthy men and women, living in Oxfordshire, randomly selected for participation through NHS number (Karpe et al., 2018). When first recruited to the cohort, all Oxford BioBank participants attended a screening visit at which they gave informed consent to be re-approached (Karpe et al., 2018). The screening visit involved a whole body DEXA scan and conventional anthropometric measurements (Karpe et al., 2018).

Recruitment was conducted in two phases. First, in 2016, 1,041 invitation letters were sent out to a random selection of Oxford BioBank participants, without knowledge of either body composition or socio-demographic background of the invitees. This study reused extant body mass index and fat mass distribution measures collected at the screening visit with the Oxford BioBank. Second, in 2018, as part of another study specifically focusing on body fat distribution, a further 174 participants were recruited to take the questionnaire. For this second study, participants were selected from the outer terciles of fat distribution in equal numbers within two predefined BMI strata (below and above $27 \mathrm{~kg} / \mathrm{m} 2$ ); however, recruitment was conducted without knowledge of participants' sociodemographic background. For the present pilot analysis, data from both groups were brought together into a single dataset.

Participants were invited to take the questionnaire online, through a secure webpage created on the Oxford BioBank website; participants also had the option of requesting that a paper copy of the questionnaire be sent to them. The study was reviewed and approved by the School of Anthropology and Museum Ethnography Research Ethics Committee (SAME REC) in accordance with the procedures laid down by the University of Oxford for the ethical approval of all research involving human participants. The participants provided informed consent either electronically (on the first page of the online questionnaire), or in writing (if they chose to complete the paper questionnaire). Questionnaire and BioBank data were anonymized through assigned participant ID numbers. In some cases, participants submitted their survey responses more than once; these duplicate data were removed, leaving only the first set of responses for each participant ID.

\section{Data analysis}

The pilot analysis focused on assessing occupational class, upward occupational social mobility, BMI and body fat distribution (measured through DEXA scanning). We subscribe to a wider view of social class - which includes social capital, assets, and economic security. However, a key aim of the pilot analysis was to determine whether using the questionnaire would lead to the expected directional effect of fat distribution in relation to paternal social 
class, and thereby support the questionnaire's future use. We therefore decided to use occupational class as our proxy variable for social class, to interpret the results in light of the extant literatures on social mobility and the social gradients of obesity, the great majority of which have relied on occupation to determine participants' social class. Paternal occupational class was selected as the proxy variable for parental social class because many participants reported their mothers were stay-at-home mothers; therefore, focusing on fathers' occupational data allowed us to increase the number of participants for whom social mobility could be calculated. Data outputs were provided in an Excel file, which was then converted into an SPSS 23 file for the purposes of recoding and analysis.

The occupations of participants and their fathers were coded according to the National Statistics Socio-Economic Classification (NS-SEC) tables, using the coding tool for analytic class categories (Office for National Statistics, n.d.). Occupations were first coded on the 8point scale, and then recoded to fit the 3-point scale, wherein occupational classes are defined as follows: Class 1 - "higher managerial, administrative and professional occupations"; Class 2 - "intermediate occupations"; Class 3 - "routine and manual occupations" (Office for National Statistics, 2010: p. 13). Occupational classes were then recoded into a binary variable (occupational class 1 and occupational classes 2 and 3). For participants' occupations, codes also took employer/employee status into account, in keeping with NSSEC. Social mobility was calculated by subtracting father's social class from participant's social class, using the 3-point scale. The resulting 5-point variable (ranging from 2 to -2), was then recoded into a 3-point variable (upward mobility, no mobility, downward mobility); this variable was further recoded into a dummy variable (upward mobility and no/downward mobility). In a few cases, it was not clear how to code a particular occupation; the first and last authors discussed these cases, together with the study's research assistant, until they achieved a consensus on how to proceed.

Measures of fatness in adulthood were obtained through matching questionnaire and extant Oxford BioBank data (BMI and DEXA scan data) by participant ID. For this analysis, BMI, height (as a measure of long-term nutritional status), and four fatness variables (total fat [percentage], android fat mass, gynoid fat mass and android visceral fat mass [in grams]) were selected. Using the android (abdominal/trunk) fat mass and gynoid (gluteofemoral) fat mass data, we computed a new variable to obtain the ratio of android to gynoid fat mass. The selection of android fat mass and gynoid fat mass as key variables of regional adiposity was informed by the literature on the higher risks associated with android fat mass, as well as by the associations between chronic stress and android fat mass (Dallman et al., 2005). BMI data were available for all participants, while fatness data were available for most, but not all, since not all Oxford BioBank participants have undergone DEXA scanning.

The sample was divided into female and male subsamples, and sex-specific ANOVA analyses were conducted via SPSS 23 to assess the following associations:

1. Participant social class and adiposity measures;

2. Paternal social class and adiposity measures;

3. Upward occupational mobility relative to father and adiposity measures.

\section{Results}


In total, after duplicates were removed, 280 Oxford BioBank participants (166 women and 114 men; age $32-67$ years at the time of questionnaire completion; mean age 47.7 years, median age 49 years) completed the questionnaire. The participants' occupational class, paternal occupational class, and occupational mobility frequencies are provided in Table 1.

As shown in Table 2, men of occupational classes $2 \& 3$ had significantly higher mean BMI compared to men of occupation class 1 . However, participant occupational class was not significantly associated with any of the fatness measures among men, although these moved in the expected direction. Among women, no significant associations were found between participant occupational class and any of the obesity measures, and the expected direction of these measures was reversed (Table 2).

Men whose father was of occupational class 2 or 3 had significantly higher mean BMI, total body fat percentage, android fat mass, and android to gynoid fat mass ratio (Table 3 ). Women whose father was of occupational class 2 or 3 had significantly higher mean BMI, total body fat percentage, android fat mass, and gynoid fat mass. No significant associations were observed between father's occupational class and women's android to gynoid fat mass ratio, although the expected direction of association was demonstrated (Table 3 ).

Upward occupational mobility was not significantly associated with fatness measures among men (Table 4). Among women, upward occupational mobility was significantly associated with several fatness measures: women who were upwardly mobile compared to their fathers had significantly higher total body fat percentage, android fat mass, and gynoid fat mass. No significant associations were observed between women's upward social mobility and BMI (Table 4).

\section{Discussion}

Designed as a pilot, the study investigated how occupational class and mobility items in a new socioepidemiological questionnaire performed with respect to the expected directional effect of body fat distribution. The results demonstrated the expected directional effect, with two key findings. First, the analysis shows that, for both men and women, father's occupational class is significantly and inversely associated with adiposity, whereas associations between participant's occupational class and adiposity appear to be weaker. This suggests that social class of origin may have a greater impact on fatness and health risk than social class of destination. Notably, these findings are partially consistent with another UKbased study, where significant inverse associations between paternal occupational class and fat mass and android-to-gynoid fat ratios were identified among both women and men aged 60-64 years (Bann et al., 2014). Second, the analysis shows that associations between social mobility and adiposity vary considerably between men and women. No associations between upward social mobility and adiposity were observed among men. This, combined with the significant associations observed between father's occupational social class and men's android fatness, suggests that upward mobility might not influence the health effects of childhood social class among men, thereby aligning with previous research on obesity and social mobility (Heraclides \& Brunner, 2010). However, the picture is different for women: upwardly mobile women have significantly higher total body fat percentage, android fat mass, and gynoid fat mass. Given that overall body fatness is strongly associated with lowgrade systemic inflammation in women (Thorand et al 2011, Varghese et al 2017), these 
results suggest that upward mobility among women might actually be associated with adverse health outcomes. Moreover, a comparison of variances in fatness measures highlights potentially important differences between men's and women's class-related experiences. Whereas these variances were higher among men of occupational class $2 \& 3$ compared to men of occupational class 1, suggesting possible social pressure for 'size conformity' among the latter, similar differences in variances were not observed among women. This suggests that men in occupational class 1 might represent a more cohesive SES group compared to women in occupational class 1 .

The findings point to the complex pathways that connect social class and health inequalities among women - pathways for which previous social mobility studies have not accounted. The observed associations between women's upward social mobility and fatness measures may be explained, at least in part, by qualitative sociological analyses which describe women's experiences of upward social mobility as potentially traumatic, leading to "unease, anxiety and dislocation" (Friedman, 2016: 130). This literature suggests that, because societal narratives of upward mobility are male-oriented, upwardly mobile women may suffer from social displacement (Lawler, 1999; Walkerdine, 2003), and that educationally upwardly mobile girls may suffer from increased bullying among both their communities of origin and their communities of destination (Brine, 2004; Friedman, 2016; Reay, 1998), thereby leading to chronic stress and poorer health.

While significant associations were observed between women's fatness measures and upward mobility, no such association was observed for BMI. Moreover, whereas a significant inverse association was observed between men's BMI and occupational class, BMI was not associated with women's occupational class. These findings seem to suggest BMI might be an insufficient proxy when examining relationships between women's social class and health risk outcomes. This might be because, at any BMI, females have a greater proportion of body weight as fat and a greater proportion of fat in the lower body than males. Additionally, the BMI proxy for body fatness for women is influenced by life history events - pregnancy and breast feeding - making it potentially less reliable in a post-parous female population (Garaulet et al. 2000). Having said that, a significant inverse association was observed between women's BMI and father's occupational class. This suggests that another possible explanation may be rooted in the complexity of using occupational class as a proxy for women's socioeconomic status. Although occupation is a robust proxy for socioeconomic status among men, previous reviews have found that it is an incomplete proxy for socioeconomic status among women, due to women's non-linear career trajectories, part-time and precarious employment, unpaid caregiving work, and glass ceilings in paid employment (Reid, 2002; Shavers, 2007).

The study has several limitations related to its sample size. Namely, the study is limited by the comparatively low number of male participants, as well as by the low numbers of participants from occupational class 3 . Relative to the UK average, the study included a large proportion of participants with higher managerial, administrative, and professional occupations, likely due to the study's Oxfordshire location (Nomis, 2020). Moreover, the observed rates of upward mobility were somewhat higher than reported national rates, although, notably, the observed rates of downward mobility were consistent with the prevalence of downward mobility among UK men in 1972-2005 (Goldthorpe and Mills, 2008). In addition, the analysis of fat distribution was limited by the fact that not all Oxford 
BioBank participants have taken part in DEXA scanning, as well as by the absence of adequately measured confounders known to affect adiposity, such as smoking and alcohol intake. Given the small sample size, many comparisons were underpowered, with the power cut-off for significant findings being between $62.2 \%$ of $62.7 \%$, suggesting that, with a larger sample size, additional findings might have emerged as significant. Furthermore, regression analysis, which would have allowed to adjust for confounders, such as parental education and occupation, was not performed because the sample did not have sufficient power. However, because this study was designed as a pilot, the results are interpreted with the intention to guide future, larger-scale research, rather than provide definitive answers.

\section{Conclusion and future directions}

Social class of origin may have a greater impact on fatness and health risk than social class of destination for both men and women. Associations between upward social mobility and fat distribution vary considerably between men and women, with upwardly mobile women having significantly higher body fat percentage, android fat mas and gynoid fat mass, compared to their non-socially mobile and downwardly mobile peers. Taken together, the findings suggest that future studies should include longitudinal measurements, to understand better the exposures and mediators that lead to adiposity and altered regional fat distribution. Importantly, future research should account for complex associations between gender, social class, social mobility, and health outcomes. For example, McLaren and Kuh (2004) note the importance of distinguishing between education, occupation, current social class and intergenerational social mobility when examining the production of body dissatisfaction among women. Indeed, understanding how women's social mobility intersect with health outcomes relies on filling the extant gaps in social mobility instruments, and including education, social capital, and insecurity variables alongside the more 'traditional' variables of occupation and income. In accounting for complexity and bridging qualitative and quantitative understandings of social mobility, the new Socioepidemiological Questionnaire can pave the way for future studies on how early life exposures relate to chronic disease in adulthood.

\section{Acknowledgments}

We would like to thank the Oxford BioBank participants who took part in this study. We would also like to thank Jane Cheeseman, Louise Dennis, John Miller, and Matthew Neville for their help with participant recruitment and data collection; Keiko Kanno, for her help with coding occupational classes; and Christina de Bellaigue, Charlotte Bennett, Tess Bird, and Eve Worth for their insights on women's social mobility.

\section{Table 1: Sample characteristics}

\begin{tabular}{|l|l|l|}
\hline Men & Women \\
\hline
\end{tabular}




\begin{tabular}{|c|c|c|c|c|c|c|c|c|c|}
\hline & & Mean & Median & Min & $\operatorname{Max}$ & Mean & Mediar & Min & $\operatorname{Max}$ \\
\hline $\begin{array}{l}\text { Age at questio } \\
\text { completion (in }\end{array}$ & $\begin{array}{l}\text { naire } \\
\text { ears) }\end{array}$ & 48 & 49 & 32 & 64 & 47.5 & 49 & 33 & 67 \\
\hline & & & $\mathrm{N}$ & & $\%$ & & $\overline{\mathrm{N}}$ & & $\%$ \\
\hline Father's & I & & 36 & & 35.6 & & 60 & & 39.2 \\
\hline occupational & II & & 33 & & 32.7 & & 42 & & 27.5 \\
\hline & III & & 32 & & 31.7 & & 51 & & 33.3 \\
\hline & Total & & 101 & & 100 & & 153 & & 100 \\
\hline Participant & I & & 73 & & 66.4 & & 92 & & 56.4 \\
\hline occupational & II & & 19 & & 17.3 & & 54 & & 33.1 \\
\hline & III & & 18 & & 16.4 & & 17 & & 10.2 \\
\hline & Total & & 110 & & 100 & & 163 & & 100 \\
\hline Mobility & Downward & & 14 & & 14.1 & & 27 & & 18.0 \\
\hline relative to & No change & & 40 & & 40.4 & & 52 & & 34.7 \\
\hline & Upward & & 45 & & 45.5 & & 71 & & 47.3 \\
\hline & Total & & 99 & & 100 & & 150 & & 100 \\
\hline
\end{tabular}

\pm I - higher managerial, administrative and professional occupations; II - intermediate occupations; III - routine and manual occupations 
Table 2: Occupational class and obesity measures

\begin{tabular}{|c|c|c|c|c|c|c|c|}
\hline & & Occupational class \pm & $\mathbf{N}$ & Mean & Std. Deviation & $\mathbf{F}$ & Sig. \\
\hline \multirow{14}{*}{ Men } & \multirow[t]{2}{*}{ BMI** } & $\mathrm{I}$ & 73 & 25.42 & 2.77 & 8.069 & 0.005 \\
\hline & & II and III & 37 & 27.48 & 4.82 & & \\
\hline & \multirow[t]{2}{*}{ Height, $\mathrm{cm}$} & $\mathrm{I}$ & 73 & 178.88 & 5.67 & 1.731 & 0.191 \\
\hline & & II and III & 37 & 177.32 & 6.19 & & \\
\hline & \multirow[t]{2}{*}{ Tissue total, \% fat } & $\mathrm{I}$ & 68 & 26.29 & 6.70 & 0.406 & 0.526 \\
\hline & & II and III & 31 & 27.28 & 8.08 & & \\
\hline & \multirow[t]{2}{*}{ Fat mass android, $g$} & $\mathrm{I}$ & 68 & 1975.50 & 964.83 & 2.305 & 0.132 \\
\hline & & II and III & 31 & 2366.58 & 1577.80 & & \\
\hline & \multirow[t]{2}{*}{ Fat mass gynoid, $\mathrm{g}$} & $\mathrm{I}$ & 68 & 3096.48 & 991.56 & 1.007 & 0.318 \\
\hline & & II and III & 31 & 3346.01 & 1435.06 & & \\
\hline & \multirow{2}{*}{$\begin{array}{l}\text { Fat mass android } \\
\text { visceral, } \mathrm{g}\end{array}$} & I & 68 & 998.61 & 679.92 & 2.169 & 0.144 \\
\hline & & II and III & 30 & 1252.69 & 991.25 & & \\
\hline & \multirow{2}{*}{$\begin{array}{l}\text { Android-gynoid fat } \\
\text { mass ratio }\end{array}$} & $\mathrm{I}$ & 68 & 0.6122 & 0.18 & 1.097 & 0.298 \\
\hline & & II and III & 31 & 0.6546 & 0.20 & & \\
\hline \multirow{14}{*}{ Women } & \multirow[t]{2}{*}{ BMI } & $\mathrm{I}$ & 92 & 25.82 & 4.29 & 0.415 & .520 \\
\hline & & II and III & 71 & 25.42 & 3.51 & & \\
\hline & \multirow[t]{2}{*}{ Height, $\mathrm{cm}$} & $\mathrm{I}$ & 92 & 166.89 & 6.91 & .253 & .616 \\
\hline & & II and III & 71 & 166.34 & 7.03 & & \\
\hline & \multirow[t]{2}{*}{ Tissue total, $\%$ fat } & $\mathrm{I}$ & 76 & 37.98 & 6.80 & 1.497 & 0.233 \\
\hline & & II and III & 61 & 36.55 & 6.84 & & \\
\hline & \multirow[t]{2}{*}{ Fat mass android, $\mathrm{g}$} & $\mathrm{I}$ & 76 & 2143.04 & 1066.65 & 2.690 & 0.103 \\
\hline & & II and III & 61 & 1855.22 & 960.47 & & \\
\hline & \multirow[t]{2}{*}{ Fat mass gynoid, g } & I & 76 & 4866.53 & 1414.91 & 0.757 & 0.386 \\
\hline & & II and III & 61 & 4662.02 & 1305.97 & & \\
\hline & \multirow{2}{*}{$\begin{array}{l}\text { Fat mass android } \\
\text { visceral, } g\end{array}$} & $\mathrm{I}$ & 76 & 539.13 & 464.80 & 1.950 & 0.165 \\
\hline & & II and III & 61 & 427.57 & 464.55 & & \\
\hline & \multirow{2}{*}{$\begin{array}{l}\text { Android-gynoid fat } \\
\text { mass ratio }\end{array}$} & $\mathrm{I}$ & 76 & 0.43 & 0.15 & 2.132 & 0.147 \\
\hline & & II and III & 61 & 0.39 & 0.16 & & \\
\hline
\end{tabular}

\pm I - higher managerial, administrative and professional occupations; II - intermediate occupations;

III - routine and manual occupations $* p \leq .05 ; * * p \leq .01$ 
Table 3: Father's occupational class and obesity measures

\begin{tabular}{|c|c|c|c|c|c|c|c|}
\hline & & $\begin{array}{l}\text { Father's } \\
\text { occupational class } \pm\end{array}$ & $\mathrm{N}$ & Mean & Std. Deviation & $\mathrm{F}$ & Sig. \\
\hline \multirow{14}{*}{ Men } & \multirow[t]{2}{*}{$\mathrm{BMI}^{*}$} & I & 36 & 24.95 & 3.12 & 5.600 & 0.020 \\
\hline & & II and III & 65 & 26.78 & 4.02 & & \\
\hline & \multirow[t]{2}{*}{ Height } & $\mathrm{I}$ & 36 & 179.11 & 6.13 & 0.709 & 0.402 \\
\hline & & II and III & 65 & 178.08 & 5.79 & & \\
\hline & \multirow{2}{*}{$\begin{array}{l}\text { Tissue total, } \\
\% \text { fat* }\end{array}$} & I & 33 & 24.51 & 7.06 & 5.107 & 0.026 \\
\hline & & II and III & 59 & 27.98 & 7.07 & & \\
\hline & \multirow{2}{*}{$\begin{array}{l}\text { Fat mass } \\
\text { android, } \mathrm{g}^{*}\end{array}$} & $\mathrm{I}$ & 33 & 1761.79 & 988.20 & 4.419 & 0.038 \\
\hline & & II and III & 59 & 2307.61 & 1294.19 & & \\
\hline & \multirow{2}{*}{$\begin{array}{l}\text { Fat mass } \\
\text { gynoid, g }\end{array}$} & I & 33 & 2896.93 & 1036.21 & 3.543 & 0.063 \\
\hline & & II and III & 59 & 3369.45 & 1215.64 & & \\
\hline & \multirow{2}{*}{$\begin{array}{l}\text { Fat mass } \\
\text { android } \\
\text { visceral, } \mathrm{g}\end{array}$} & I & 33 & 888.72 & 661.68 & 2.748 & 0.101 \\
\hline & & II and III & 58 & 1172.52 & 846.60 & & \\
\hline & \multirow{2}{*}{$\begin{array}{l}\text { Android- } \\
\text { gynoid fat } \\
\text { mass ratio* }\end{array}$} & I & 33 & 0.65 & 0.18 & 4.194 & 0.043 \\
\hline & & II and III & 58 & 0.57 & 0.20 & & \\
\hline \multirow{14}{*}{ Women } & \multirow[t]{2}{*}{ BMI* $^{*}$} & I & 60 & 24.67 & 3.59 & 5.695 & 0.018 \\
\hline & & II and III & 93 & 26.20 & 4.04 & & \\
\hline & \multirow[t]{2}{*}{ Height, cm } & I & 60 & 166.20 & 6.88 & 0.315 & 0.576 \\
\hline & & II and III & 93 & 166.85 & 7.06 & & \\
\hline & \multirow{2}{*}{$\begin{array}{l}\text { Tissue total, } \\
\% \text { fat* }\end{array}$} & $\mathrm{I}$ & 49 & 35.56 & 7.07 & 6.088 & 0.015 \\
\hline & & II and III & 80 & 38.53 & 6.36 & & \\
\hline & \multirow{2}{*}{$\begin{array}{l}\text { Fat mass } \\
\text { android, } \mathrm{g}^{*}\end{array}$} & I & 49 & 1735.58 & 1008.98 & 5.647 & 0.019 \\
\hline & & II and III & 80 & 2168.23 & 1000.30 & & \\
\hline & \multirow{2}{*}{$\begin{array}{l}\text { Fat mass } \\
\text { gynoid, g* }\end{array}$} & I & 49 & 4424.84 & 1341.91 & 5.749 & 0.018 \\
\hline & & II and III & 80 & 4986.74 & 1260.36 & & \\
\hline & \multirow{2}{*}{$\begin{array}{l}\text { Fat mass } \\
\text { android } \\
\text { visceral, g }\end{array}$} & I & 49 & 421.82 & 554.15 & 1.633 & 0.204 \\
\hline & & II and III & 80 & 531.17 & 413.78 & & \\
\hline & \multirow{2}{*}{$\begin{array}{l}\text { Android- } \\
\text { gynoid fat } \\
\text { mass ratio }\end{array}$} & I & 49 & 0.38 & 0.14 & 3.278 & 0.073 \\
\hline & & II and III & 80 & 0.43 & 0.16 & & \\
\hline
\end{tabular}

\pm I - higher managerial, administrative and professional occupations; II - intermediate occupations; III - routine and manual occupations * $p \leq .05 ; * * p \leq .01$ 
Table 4: Upward occupational mobility compared to father and obesity measures

\begin{tabular}{|c|c|c|c|c|c|c|c|}
\hline & & $\begin{array}{l}\text { Upward mobility } \\
\text { (occupational) }\end{array}$ & $\mathrm{N}$ & Mean & Std. Deviation & $\mathrm{F}$ & Sig. \\
\hline \multirow{14}{*}{ Men } & \multirow[t]{2}{*}{ BMI } & Yes & 45 & 26.20 & 2.82 & 0.085 & 0.772 \\
\hline & & No & 54 & 25.98 & 4.44 & & \\
\hline & \multirow[t]{2}{*}{ Height } & Yes & 45 & 178.71 & 5.65 & 0.118 & 0.732 \\
\hline & & No & 54 & 178.30 & 6.23 & & \\
\hline & \multirow{2}{*}{$\begin{array}{l}\text { Tissue total, } \\
\% \text { fat }\end{array}$} & Yes & 42 & 27.53 & 6.01 & 1.116 & 0.294 \\
\hline & & No & 48 & 25.91 & 8.19 & & \\
\hline & \multirow{2}{*}{$\begin{array}{l}\text { Fat mass } \\
\text { android, } g\end{array}$} & Yes & 42 & 2155.09 & 911.99 & 0.132 & 0.718 \\
\hline & & No & 48 & 2061.43 & 1438.49 & & \\
\hline & \multirow{2}{*}{$\begin{array}{l}\text { Fat mass } \\
\text { gynoid, g }\end{array}$} & Yes & 42 & 3258.21 & 899.04 & 0.242 & 0.624 \\
\hline & & No & 48 & 3135.35 & 1380.97 & & \\
\hline & \multirow{2}{*}{$\begin{array}{l}\text { Fat mass } \\
\text { android } \\
\text { visceral, g }\end{array}$} & Yes & 42 & 1087.55 & 677.88 & 0.044 & 0.834 \\
\hline & & No & 47 & 1051.96 & 893.97 & & \\
\hline & \multirow{2}{*}{$\begin{array}{l}\text { Android- } \\
\text { gynoid fat } \\
\text { mass ratio }\end{array}$} & Yes & 42 & 0.65 & 0.17 & 1.092 & 0.299 \\
\hline & & No & 48 & 0.60 & 0.20 & & \\
\hline \multirow{14}{*}{ Women } & \multirow[t]{2}{*}{ BMI } & Yes & 71 & 26.16 & 4.24 & 2.633 & 0.107 \\
\hline & & No & 79 & 25.12 & 3.62 & & \\
\hline & \multirow[t]{2}{*}{ Height, cm } & Yes & 71 & 167.31 & 7.15 & 1.656 & 0.200 \\
\hline & & No & 79 & 165.84 & 6.88 & & \\
\hline & \multirow{2}{*}{$\begin{array}{l}\text { Tissue total, } \\
\% \text { fat* }\end{array}$} & Yes & 60 & 38.93 & 6.71 & 5.136 & 0.025 \\
\hline & & No & 66 & 36.25 & 6.55 & & \\
\hline & \multirow{2}{*}{$\begin{array}{l}\text { Fat mass } \\
\text { android, g* }\end{array}$} & Yes & 60 & 2237.45 & 1056.64 & 5.317 & 0.023 \\
\hline & & $\mathrm{No}$ & 66 & 1823.60 & 958.08 & & \\
\hline & \multirow{2}{*}{$\begin{array}{l}\text { Fat mass } \\
\text { gynoid, } \mathrm{g}^{* *}\end{array}$} & Yes & 60 & 5107.64 & 1308.48 & 7.433 & 0.007 \\
\hline & & No & 66 & 4482.87 & 1262.78 & & \\
\hline & \multirow{2}{*}{$\begin{array}{l}\text { Fat mass } \\
\text { android } \\
\text { visceral, } \mathrm{g}\end{array}$} & Yes & 60 & 548.82 & 430.88 & 1.443 & 0.232 \\
\hline & & No & 66 & 446.94 & 512.56 & & \\
\hline & \multirow{2}{*}{$\begin{array}{l}\text { Android- } \\
\text { gynoid fat } \\
\text { mass ratio }\end{array}$} & Yes & 60 & 0.43 & 0.15 & 1.152 & 0.285 \\
\hline & & No & 66 & 0.40 & 0.16 & & \\
\hline
\end{tabular}

$* p \leq .05 ; * * p \leq .01$ 


\section{References}

1. Ball, K., \& Mishra, G. D. (2006). Whose socioeconomic status influences a woman's obesity risk: her mother's, her father's, or her own? International Journal of Epidemiology, 35(1), 131-138.

2. Bann, D., Cooper, R., Wills, A. K., Adams, J., \& Kuh, D. (2014). Socioeconomic position across life and body composition in early old age: findings from a British birth cohort study. $J$ Epidemiol Community Health, 68(6), 516-523.

3. Bredella, M.A. (2017). Sex differences in body composition. In F. Mauvais-Jarvis (ed.), Sex and Gender Factors Affecting Metabolic Homeostasis, Diabetes and Obesity. Advances in Experimental Medicine and Biology 1043, https://doi.org/10.1007/978-3-319-70178-3_2

4. Blane, D., Harding, S., \& Rosato, M. (1999). Does social mobility affect the size of the socioeconomic mortality differential?: evidence from the Office for National Statistics Longitudinal Study. Journal of the Royal Statistical Society: Series A (Statistics in Society), 162(1), 59-70.

5. Brine, Jacky. "Tales of the 50-somethings: selective schooling, gender and social class." Gender and Education 18, no. 4 (2006): 431-446.

6. Centers for Disease Control and Prevention. (2000). Measuring healthy days: Population assessment of health-related quality of life. Atlanta, GA: Centers for Disease Control and Prevention.

7. Dallman, M. F., Pecoraro, N. C., \& la Fleur, S. E. (2005). Chronic stress and comfort foods: self-medication and abdominal obesity. Brain, behavior, and immunity, 19(4), 275-280.

8. Friedman, Sam. "Habitus clivé and the emotional imprint of social mobility." The Sociological Review 64, no. 1 (2016): 129-147.

9. Friedman, Sam. "Habitus clivé and the emotional imprint of social mobility." The Sociological Review 64, no. 1 (2016): 129-147.

10. Garaulet, M., Perex-Llamas, F., Fuente, T., Zamora, S., \& Tebar, F. J. (2000). Anthropometric, computed tomography and fat cell data in an obese population: relationship with insulin, leptin, tumor necrosis factor-alpha, sex hormone-binding globulin and sex hormones. European Journal of Endocrinology, 143(5), 657-666.

11. Giskes, K., Lenthe, F. J., Turrell, G., Kamphuis, C., Brug, J., \& Mackenbach, J. P. (2008). Socioeconomic position at different stages of the life course and its influence on body weight and weight gain in adulthood: a longitudinal study with 13-year follow-up. Obesity, 16(6), 1377-1381.

12. Goldthorpe, J. H., \& McKnight, A. (2006). The economic basis of social class. In Mobility and Inequality: Frontiers of Research in Sociology and Economics, Morgan, S.L, Grusky, D.B., and Fields, G.S. (Eds.), 109-136.

13. Goldthorpe, J. H., \& Mills, C. (2008). Trends in intergenerational class mobility in modern Britain: evidence from national surveys, 1972-2005. National Institute Economic Review, 205(1), 83-100.

14. Hahn, R. A., \& Inhorn, M. C. (eds.) (2009). Anthropology and Public Health: Bridging Differences in Culture and Society. Oxford University Press.

15. Heraclides, A., \& Brunner, E. (2010). Social mobility and social accumulation across the life course in relation to adult overweight and obesity: the Whitehall II study. Journal of Epidemiology and Community Health, 64(8), 714-719.

16. Karastergiou, K., \& Fried, S.K. (2017). Cellular mechanisms driving sex differences in adipose tissue biology and body shape in humans and mouse models. In F. Mauvais-Jarvis (ed.), Sex and Gender Factors Affecting Metabolic Homeostasis, Diabetes and Obesity. Advances in Experimental Medicine and Biology 1043, https://doi.org/10.1007/978-3-31970178-3_3 
17. Karpe, F. \& Pinnick, K.E. (2015). Biology of upper-body and lower-body adipose tissuelink to whole-body phenotypes. Nature Reviews Endocrinology 11, 90-100.

18. Karpe, F., Vasan, S. K., Humphreys, S. M., Miller, J., Cheeseman, J., Dennis, A. L., \& Neville, M. J. (2018). Cohort profile: the Oxford biobank. International journal of epidemiology, 47(1), 21-21g.

19. Karvonen, S., Rimpelä, A. H., \& Rimpelä, M. K. (1999). Social mobility and health related behaviours in young people. Journal of Epidemiology and Community Health, 53(4), 211217.

20. Kestila, L., Rahkonen, O., Martelin, T., Lahti-Koski, M., \& Koskinen, S. (2009). Do childhood social circumstances affect overweight and obesity in early adulthood? Scandinavian Journal of Public Health, 37(2), 206-219.

21. Langenberg, C., Hardy, R., Kuh, D., Brunner, E., \& Wadsworth, M. (2003). Central and total obesity in middle aged men and women in relation to lifetime socioeconomic status: evidence from a national birth cohort. Journal of Epidemiology and Community Health, 57(10), 816822.

22. Langenberg, C., Kuh, D., Wadsworth, M. E., Brunner, E., \& Hardy, R. (2006). Social circumstances and education: life course origins of social inequalities in metabolic risk in a prospective national birth cohort. American Journal of Public Health, 96(12), 2216.

23. Lawler, S. (1999). 'Getting out and getting away': Women's narratives of class mobility. Feminist review, 63(1), 3-24.

24. Li, Y., Savage, M., \& Warde, A. (2008). Social mobility and social capital in contemporary Britain. The British Journal of Sociology, 59(3), 391-411.

25. McLaren, L., \& Kuh, D. (2004). Women's body dissatisfaction, social class, and social mobility. Social Science \& Medicine, 58(9), 1575-1584.

26. Marmot, M., Ryff, C. D., Bumpass, L. L., Shipley, M., \& Marks, N. F. (1997). Social inequalities in health: next questions and converging evidence. Social Science \& Medicine, 44(6), 901-910.

27. Marmot, M., Shipley, M., Brunner, E., \& Hemingway, H. (2001). Relative contribution of early life and adult socioeconomic factors to adult morbidity in the Whitehall II study. Journal of Epidemiology and Community Health, 55(5), 301-307.

28. Nomis (2020). Labour Market Profile - Oxfordshire. Official Labour Market Statistics. https://www.nomisweb.co.uk/reports/lmp/lep/1925185557/report.aspx (accessed 27 April 2020).

29. Norris, T., Bann, D., Hardy, R., \& Johnson, W. (2020). Socioeconomic inequalities in childhood-to-adulthood BMI tracking in three British birth cohorts. International Journal of Obesity, 44(2), 388-398.

30. Office for National Statistics. (n.d.). National Statistics Socio-Economic Classification (NSSEC) Coding Tool. https://onsdigital.github.io/dp-classification-tools/standard-occupationalclassification/ONS_NSSEC_discovery_tool.html.

31. Office for National Statistics. (2010). Standard occupational classification 2010: Volume 3 : The National Statistics Socio-economic Classification: (Rebased on the SOC2010) User Manual. Palgrave Macmillan.

32. Poulton, R., Caspi, A., Milne, B. J., Thomson, W. M., Taylor, A., Sears, M. R., \& Moffitt, T. E. (2002). Association between children's experience of socioeconomic disadvantage and adult health: a life-course study. The Lancet, 360(9346), 1640-1645.

33. Power, C., \& Matthews, S. (1997). Origins of health inequalities in a national population sample. The Lancet, 350(9091), 1584-1589.

34. Rahkonen, O., Lahelma, E., \& Huuhka, M. (1997). Past or present? Childhood living conditions and current socioeconomic status as determinants of adult health. Social Science \& Medicine, 44(3), 327-336. 
35. Reay, Diane. "Surviving in dangerous places: Working-class women, women's studies and higher education." In Women's Studies International Forum, vol. 21, no. 1 (1998): pp. 11-19.

36. Reid, C. (2002). A Full measure. Towards a comprehensive model for the measurement of women's health. Vancouver: British Columbia Centre of Excellence for Women's Health.

37. Savage, M., Warde, A., \& Devine, F. (2005). Capitals, assets, and resources: some critical issues. The British Journal of Sociology, 56(1), 31-47.

38. Shavers, V. L. (2007). Measurement of socioeconomic status in health disparities research. Journal of the National Medical Association, 99(9), 1013-1023.

39. Siegrist, J., \& Marmot, M. (2004). Health inequalities and the psychosocial environmenttwo scientific challenges. Social Science \& Medicine, 58(8), 1463-1473.

40. Snijder, M. B. et al. Independent and opposite associations of waist and hip circumferences with diabetes, hypertension and dyslipidemia: the AusDiab Study. Int. J. Obes. Relat. Metab. Disord. 28, 402-409 (2004).

41. Thayer, Z. M., \& Kuzawa, C. W. (2011). Biological memories of past environments: epigenetic pathways to health disparities. Epigenetics, 6(7), 798-803.

42. Thorand, B., Baumert, J., Doring, A., Herder C., Kolb, H., Rathmann, W., Giani, G., Koenig, W., for the KORA Group. Nutrition Journal 2011; 10: 4. doi: 10.1186/1475-2891-10-4

43. Ulijaszek, S. J. (2017). Models of obesity: From ecology to complexity in science and policy (Vol. 78). Cambridge University Press.

44. Van De Mheen, H., Stronks, K., Van Den Bos, J., \& Mackenbach, J. P. (1997). The contribution of childhood environment to the explanation of socio-economic inequalities in health in adult life: a retrospective study. Social Science \& Medicine, 44(1), 13-24.

45. Varghese, M., Griffin, C. \& Singer, K. (2017). The role of sex and sex hormones in regulating obesity-induced inflammation. In F. Mauvais-Jarvis (ed.), Sex and Gender Factors Affecting Metabolic Homeostasis, Diabetes and Obesity. Advances in Experimental Medicine and Biology 1043, https://doi.org/10.1007/978-3-319-70178-3_5

46. Vasan, S.K., Osmond, C., Canoy, D., Christodoulides, C., Neville, M.J., Di Gravio, C., Fall, C.H. \& Karpe, F. (2018). Comparison of regional fat measurements by dual-energy X-ray absorptiometry and conventional anthropometry and their association with markers of diabetes and cardiovascular disease risk. International Journal of Obesity, 42(4), 850-857.

47. Yim, J-E., Heshka, S., Albu, J.B., Heymsfield, S. \& Gallagher, D. (2008). Femoral-gluteal subcutaneous and intermuscular adipose tissues have independent and opposing relationships with CVD risk. Journal of Applied Physiology 104: 700-707.

48. Yusuf, S., Hawken, S., Ounpuu, S., Bautista, L., Franzosi, M.G., Commerford, P., Lang, C.C., Rumboldt, Z., Onen, C.L., Lisheng, L., Tanomsup, S., Wangai, P. Jr, Razak, F., Sharma, A.M., Anand, S.S. \& INTERHEART Study Investigators. (2005). Obesity and the risk of myocardial infarction in 27,000 participants from 52 countries: a case-control study. Lancet $366,1640-1649$.

49. Walkerdine, V. (2003). Reclassifying upward mobility: Femininity and the neo-liberal subject. Gender and education, 15(3), 237-248.

50. WHO (2005). Constitution of the WHO. http://apps.who.int/gb/bd/PDF/bd47/EN/constitution-en.pdf?ua=1 (accessed 6 July 2018). 